\title{
Structural Model of Tendency to Use Online Payment Gateway in Online Shopping and Customer Knowledge Management (Case Study: Pasargad Bank)
}

\author{
Yazdan Jafarian $^{1} \&$ Farshid Abdi $^{2}$ \\ ${ }^{1}$ Department of Management and Economics, Science and Research Branch, Islamic Azad University, Tehran, \\ Iran \\ ${ }^{2}$ Department of Industrial Engineering ,South Tehran Branch , Islamic Azad University, Tehran, Iran \\ Correspondence: Farshid Abdi, Assistant Professor, Department of Industrial Engineering, South Tehran Branch, \\ Islamic Azad University, Tehran, Iran. E-mail: farshidabdi@azad.ac.ir.com/fa_ie@yahoo.com
}

Received: February 12, 2016

Accepted: May 5, 2016

Online Published: May 18, 2016

doi:10.5539/mas.v10n10p1

URL: http://dx.doi.org/10.5539/mas.v10n10p1

\begin{abstract}
Tendency to use online payment gateway in online is influenced by individual characteristics such as risk-taking, internet knowledge, online payment knowledge and risk of customer knowledge management tools used in payment gateway and in this study, these factors have been studied simultaneously in form of a model. In online payment, payment gateways are repeated contact point between service institutions such as banks and their customers that institutions can use this opportunity to attract new customers or increase royal customers. In addition to individual characteristics, customers are facing different tools of knowledge management such as shared databases, document repositories and work applications and these tools can have different effects on risk perception and their willingness to do online shopping using internet payment gateways. In this study, structural equation partial least squares statistical method was used. Also questionnaire was used to collect data in the given population, because customer's members of the Pasargad bank were accustomed online shopping.

In summary, risk-taking has negative and significant impact on the risk is perceived of knowledge management tools and internet knowledge was not known as a factor which have a significant negative impact on the perceived risk, but the impact of internet knowledge on preference to use online payment and online payment rather tendency to use internet payment gateway in online shopping was positive and significant. Also, the perceived risk of customer knowledge management tools has negative and significant correlation with tendency to buy using online payment in online shopping by users. On the other hand, the final conclusions of the research carried out in more detail and also practical suggestions for increasing the effectiveness of managers to use knowledge management tools in the payment gateway are presented.
\end{abstract}

Keywords: customer's knowledge management, tendency to use online payment gateway in online shopping, online payment, online knowledge

\section{Introduction}

With the advent of the World Wide Web, use of e-commerce in the early nineties was started, (Schmid, 1995) Also nowadays online shopping is growing rapidly and e-commerce has increased companies' value. On the other hand, Yao believes that Internet caused rapid growth of electronic commerce and it would alter the nature of the business. E-commerce has some benefits for organizations and organizations use some web-sites to take these benefits have that operate at high levels of e-commerce.

In today's world, everywhere is talking about e-commerce. Increasing the number of online stores, the Internet is more accessible and people are motivated to online shopping more. In the meantime, the role of Internet payment is also highlighted. Because sellers and the buyers for trouble less are more likely to have this type of payment. Due to the increasing tendency for people to online shopping in users, in other words, significant progress has been e-commerce makes banks compete to obtain the highest market share of this lucrative industry that one of most effective tools in this competitive online payment gateways that are used by banks to the online stores that the use of these tools for all three parties involved in online shopping, the seller, the bank, the buyer has many advantages over other methods of payment. 
Research shows that three factors under the general title "shopping motivations" affect people who are buying process for online shopping and to buy the same physical.

The difference in the importance of these factors in different people makes them to prefer one of two ways. One of the factors affecting the willingness of customers shopping both traditional and via the Internet is the risk that they are perceived to buy. Risk perception includes the amount that the results were not favorable for the action disappears in addition to feeling person about the possibility that the results will be unpleasant.

Neul says that the real value of organization is based on the value which is created for its customers and also value is returned to the customer. Therefore, it should be noted that the value is based on information and not necessarily more advanced technology to create value. On the other hand, if customer knowledge management carried out properly, profitability is increased. If companies turn data into knowledge for customers and then use it to build a relationship with customers, this can result loyalty which leads to profitability.

Previous studies about customer knowledge management indicate that that in most successful companies, there is an individual behind every transaction and records what customers are doing during purchase and service transactions.

Customers to cooperate with organizations need motivation. Most recently emphasis is on creating value customers as partners. Customers cooperate with the organization to create knowledge for both groups using this knowledge to create better products and value is created. In this way, both units work together with one goal and customers participate actively in the process of knowledge creation. (Pakote, 2006)

Many organizations consider knowledge management as the basis of competition and a vital part in providing services and support customers. (Shah and Mortaza, 2005) Knowledge management refers to the set of processes resulting in knowledge acquisition, retention and use, and its purpose is to exploit intellectual property in order to increase productivity, create new value and increase competitiveness. In addition, customer knowledge management capabilities to improve IT infrastructure respond strongly to our customers and to provide faster decision. (Chung et al., 2005) Smart companies seek knowledge "about" and "from" customers, online payment gateways can be repeated contact point between a bank and its customers and to help them gain the knowledge and customers. Finally, keep existing customers and attract new customers in the bank and loyalty has created.

By combining the knowledge management in e-commerce activities, as a way to manage online customer knowledge, organizations can improve their processes and increase their market share. They can have communication, coordination and collaboration among teams of knowledge (including virtual teams) Using intranet technologies and among the organizations and members of foreign manufacturers using technology to improve the Extranet. (Lopez - Nicolas and Jose Molina - Castillo, 2008) Various definitions have been proposed for e-commerce that most of them were based on past experience in the use of e-commerce. In its simplest form, it can be defined as "business transactions in an electronic format". In 1997 the European Commission has defined it as follows:

"E-commerce is based on processing and electronic transmission of data, including text, sound and image. E-commerce involves activities as diverse as electronic exchange goods and services, digital content delivery, electronic funds transfer, electronic stock trading, electronic bills of lading, commercial projects, joint engineering design, sourcing, government purchases, direct marketing services sales. "

Application areas of e-commerce is much broader than the exchange of goods, services and funds and to define it and explain the policies that should noted potential applications in addition to the actual applications. Perceived risk of online transactions recently described as the most important factor in the lack of customers attention to a simple process of online shopping transaction. (Forsythe and Shi, 2003).

In summary we can say that the Internet and e-commerce at the micro level have various effects, such as reducing search costs, reduced barriers to entry to the industry, increased competition in the market and, consequently, increase productivity, shorten the chain production and supply of goods and services. Without doubt, the outcome could reduce the price of goods and services that also explain the results of the studies. (Nicholas Lopez and Molina Kaserilo, 2008)

Customer Knowledge Management is an application of knowledge management tools and techniques to support the exchange of information between an enterprise and its customers and able company to take strategic decisions appropriate to the business. (Rowley, 2002) Of course, we still need to explain the concepts of customer knowledge and customer knowledge management in detail. (Rollins and Halyn, 2005) there is not a complete understanding of the vital role of knowledge management in gaining competitive advantage in the market and in the context of e-commerce yet. (Nicholas Lopez and Molina Kaserilo, 2008) 
In this study, we may conclude that some features of online payment has positive impact on customer perception, this means that the use of Internet-based customer knowledge management, can affect the performance of Internet payment in the form of a tendency to buy online, have a positive impact, for example, Bank of Internet shopping to get the correct product based on the alleged guarantee and after verifying the buyer to transfer funds to the seller's account action. As well as some customer knowledge management tools to collect information from customers at Internet portal is used, in some cases the first point of contact for the customer in the store at a bank may pay for the banks, have a damaging effect, because on the perceived risk from the ports affected by the customer and the customer's willingness to buy are affected. With this concept, we note that in this study it may be perceived risk of a variety of customer knowledge management tools, the success of online shopping and online payment portal using tags on propensity to influence customers. Therefore efforts have to gain a deeper understanding of customer knowledge management tools in the online payment is reached.

So problem is that the use of special tools on the website of Customer Knowledge Management Portal Bank can increase the perceived risk of the customer and thus have the opposite effect in the customer's willingness to buy online through the port. Also in the analysis, the role of other variables, such as internet knowledge, knowledge preferred online payment online payment and risk appetite is discussed in the model.

We can say, using an outside perspective of knowledge management or knowledge management client, the purpose of this research is that the banks set up ports in which to manage customer knowledge and increase the profitability of banks to increase loyalty and to provide online customer payments. Therefore, on the basis of what was said study seeks to test the theoretical model.

\section{Methodology}

This study is a correlation using "structural equation modeling". These methods in recent years due to the high flexibility compared to older methods such as regression analysis, the ability to identify and control measurement errors, analyze and test complex relationships with several independent variables, have gained popularity in research on behavioral science. (Hooman, 2008) For this purpose, all customers Customer Club of Pasargad Bank because of the experience of electronic shopping as the statistical society have been selected, the total number was 63,859 people, which is based on random sampling, simple and based on Morgan table finally 386 people voted samples were selected.

Structural equation modeling tested the model in two studies, which measure the test pattern and structure. Measurement model evaluate the reliability and validity of measurements and deals with research structures and structural model assumptions and examines the relationship between latent variables. (Chain, 1998) In the present study the second generation of structural equation modeling techniques, the method of "least squares details" to test the measurement model and hypotheses have been used. PLS method due to less dependence on the sample size and the distance of the normal distribution of the remaining measures as a powerful method known as structural equation modeling. (Chain, Markolin and Neusted, 1996) In the present study because of the originality of the model study and also because it is applied according to Chain (Markolin and Neusted, 1996; Christmas, 2005) PLS approach that is more appropriate for the purposes of this study were used.

\section{Data Collection Tools}

In order to collect data for analysis, questionnaire was used. The questionnaire consists of 35 questions Moore's using Likert scale with five items. Questionnaire was designed for club members of Pasargad Bank customers in the application Google Docs and in the Internet space.

Table 1. Classification of the questionnair

\begin{tabular}{lll}
\hline Resource & Number of questions & Variables \\
\hline 1 to 4 & Knowledge store \\
5 to 7 & Preferred online payment \\
8 to 11 & Risk taking \\
12 to 14 & Knowledge online payment \\
15 to 18 & Perceived risk associated with common data bases \\
19 to 22 & Perceived risk associated with the vessels documents \\
23 to 26 & Perceived risk associated with the application process \\
27 to 30 & Tend to use online payment gateway online purchase \\
\hline
\end{tabular}




\section{Review and Test the Measurement Model}

PLS methods like LISREL method consist of two parts. In the first part, the pattern measuring the reliability (internal consistency) and validity (divergent validity) structures and research tools discussed. To investigate the validity of Fornell and Larcker's three criteria that includes:

1. Validity of each of the items,

2. Reliability of structures and their combinations

3. Average variance extracted

About the validity of each of the items, load factor is 0.7 increased and confirmatory factor analysis shows each item in a well-defined structure. (Fornell and Larcker, 1981) To validate the combination of structures Dillon Goldstein $\left(\rho_{c}\right)$ coefficient was used. (Nonali, 1978) Since PLS Unlike conventional regression analysis uses the factor scores of subjects, taking into account the time factor in calculating the credit is necessary for each item. However, the Cronbach alpha coefficient has equal weight to the credibility of the items below, therefore $\rho_{c}$ coefficient was used. (Manuel, Francisco Felix, 2009) Acceptable values $\rho_{c}$ should be 0.7 or more. (Nonali, 1978) The third marker reliability is average of extracted variance. (Fornell and Larcker, 1981) Fornell and Larcker recommended AVE 0.5 and higher, and this means that the structure explain about $50 \%$ or more of variance markers. Table 1 shows factor loadings, $\rho_{c}$ and AVE each of the structures. Table 1 shows the adequate values of structures.

Table 2. Evaluation of reliability of research structures

\begin{tabular}{|c|c|c|c|c|c|c|c|c|c|}
\hline $\begin{array}{l}\text { Factor } \\
\text { loading }\end{array}$ & Item & $\begin{array}{l}\text { Factor } \\
\text { loading }\end{array}$ & Item & $\begin{array}{l}\text { Factor } \\
\text { loading }\end{array}$ & Item & $\begin{array}{l}\text { Factor } \\
\text { loading }\end{array}$ & Item & $\begin{array}{l}\text { Factor } \\
\text { loading }\end{array}$ & Item \\
\hline 0.80 & 15 & 0.88 & 12 & 0.87 & 9 & 0.90 & 5 & 0.90 & 1 \\
\hline 0.79 & 16 & 0.92 & 13 & 0.92 & 10 & 0.80 & 6 & 0.90 & 2 \\
\hline 0.82 & 17 & 0.87 & 14 & 0.88 & 11 & 0.88 & 7 & 0.87 & 3 \\
\hline 0.90 & 18 & - & & - & & 0.79 & 8 & 0.79 & 4 \\
\hline 0.90 & & 0.92 & & 0.92 & & 0.92 & & 0.92 & )CR $\rho_{c}($ \\
\hline 0.87 & & 0.79 & & 0.76 & & 0.76 & & 0.76 & AVE \\
\hline \multirow[t]{8}{*}{0.79} & & 0.87 & & 0.89 & & 0.87 & & 0.89 & $\alpha$ \\
\hline & & & & 0.85 & 27 & 0.88 & 23 & 0.87 & 19 \\
\hline & & & & 0.92 & 28 & 0.73 & 24 & 0.76 & 20 \\
\hline & & & & 0.85 & 29 & 0.89 & 25 & 0.71 & 21 \\
\hline & & & & 0.70 & 30 & 0.90 & 26 & 0.91 & 22 \\
\hline & & & & 0.90 & & 0.83 & & 0.89 & ) $\rho_{\mathrm{c}} \mathrm{CR}($ \\
\hline & & & & 0.70 & & 0.89 & & 0.78 & AVE \\
\hline & & & & 0.79 & & 0.71 & & 0.77 & $\alpha$ \\
\hline
\end{tabular}

To examine the validity of structures, Fornell and Larcker recommend that a structure should AVE square root of its correlation with other structures. This indicates that the correlation of structure with its attributes is more than relationship with other structures. The results of this criterion are provided in Table 2, which shows structures are reliable enough.

Table 3. Matrix of correlation and root index AVE research variables

\begin{tabular}{|c|c|c|c|c|c|c|c|}
\hline 6 & 5 & 4 & 3 & 2 & 1 & Variable & $\mathrm{n}$ \\
\hline & & & & & 0.87 & Knowledge Internet & 1 \\
\hline & & & & 0.88 & $0.57^{* *}$ & Preferred online payment & 2 \\
\hline & & & 0.89 & $0.67 * *$ & $0.59^{* *}$ & Knowledge online payment & 3 \\
\hline & & 0.87 & $0.63 * *$ & $0.46^{* *}$ & $0.65^{* *}$ & Risk taking & 4 \\
\hline & 0.84 & $0.16^{* *}$ & $0.12^{*}$ & 0.09 & $-0.19 * *$ & Perceived risk management tool knowledge & 5 \\
\hline 0.84 & $-0.25 * *$ & $0.45 * *$ & $0.57 * *$ & $0.54 * *$ & $0.60^{* *}$ & Feel free to use the payment gateway & 6 \\
\hline
\end{tabular}


Results of table 2 shows the relationship between willingness to use online payment gateway and all significant variables is positive, only the relationship of these variables with perceived risk $(-0.25)$ is negative and significant relationship with perceived risks of the Internet $(-0.19)$ significant negative and prefer online shopping (-0.90) is negative and significant, also with knowledge payment $(0.12)$ and Risk taking (0.16) positively is significant. The relationship between risk-taking, shopping preference, knowledge Internet as well as payment knowledge is significant and positive. On the other hand AVE square root of each of the structures, most of the correlation between structures with other structures is indicative of the validity of instruments is appropriate

\section{Structural Model Test}

PLS structural model and research hypotheses are possible by examining the Path coefficients and values of variance R2. (Vinzi, Chain, Hansler and Wang, 2010) Also autonomous method (with 200 sub-samples) was used to calculate the values $\mathrm{T}$ to determine the significance of path. Path coefficients are used to determine the contribution of each of predictive variables in explaining the variance in the criteria and R2 values indicate the criterion variable variance explained by the predictor variables. (Vinzi, et al., 2010) The present study tested the model shown in Figure 2.

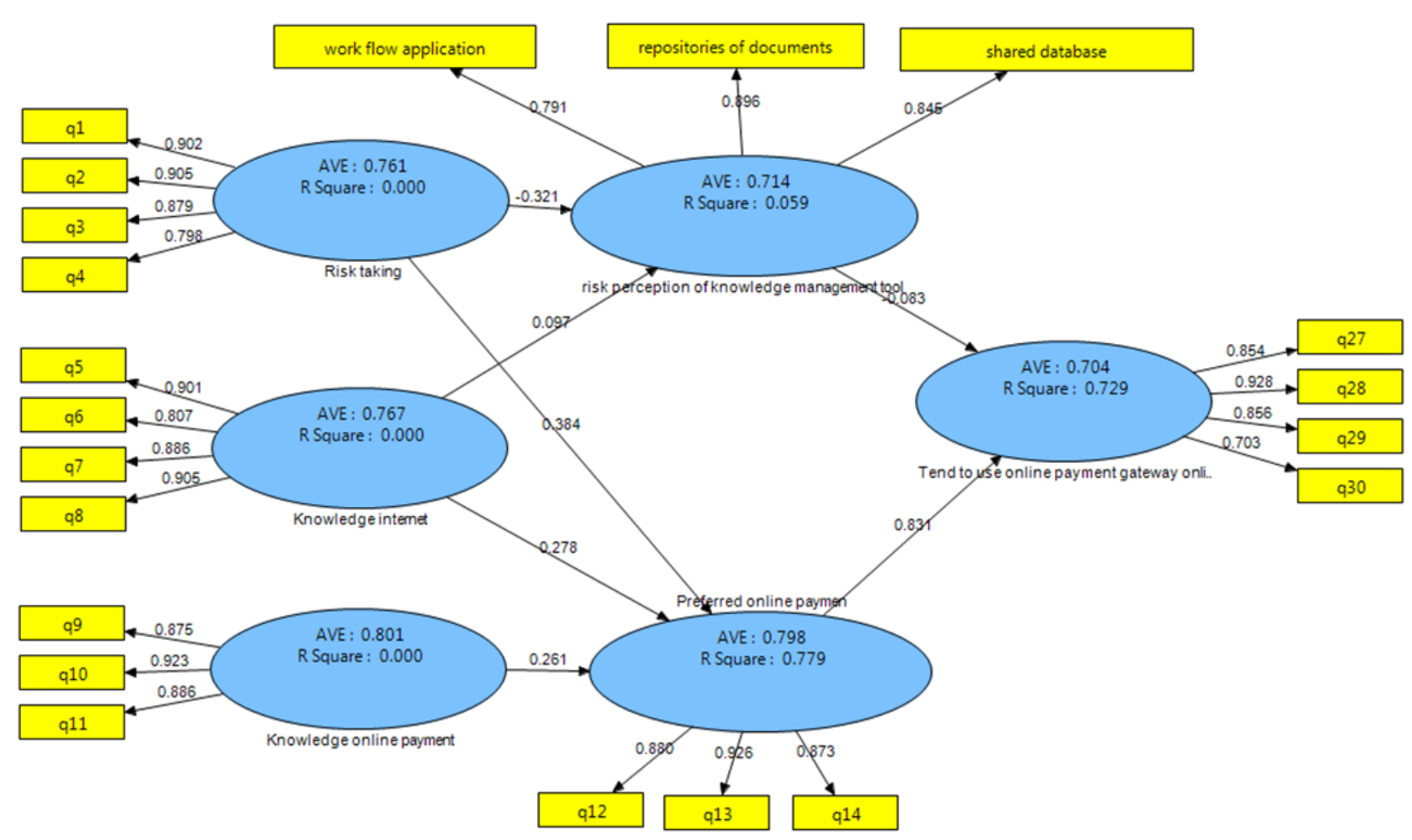

Figure 1. A test Model of the present study

\section{Review Hypotheses}

In Table 4 results of the structural model to assess the significance of paths, beta coefficients, variance in order to check the hypotheses presented.

Table 4. direct effects, beta coefficients and explained variance of the variables under study hypotheses structural model

\begin{tabular}{|c|c|c|c|c|c|}
\hline Result & Hypotheses & & & & Number \\
\hline & Coefficient of determination & Statistict & Effect coefficient & Hypotheses & \\
\hline Accepted & Toward perceived risk 0.06 & 2.90 & $-0.32 * *$ & $\begin{array}{l}\text { Risk taking }>\text { Risk perception of knowledge } \\
\text { management tool }\end{array}$ & \\
\hline Denied & & 0.96 & 0.09 & Knowledge internet> risk perception of & 2 \\
\hline
\end{tabular}


knowledge management tool

\begin{tabular}{|c|c|c|c|c|c|c|}
\hline Accepted & \multirow{3}{*}{$\begin{array}{l}\text { Toward online } \\
\text { preference } 0.79\end{array}$} & \multirow[t]{3}{*}{ payment } & 4.08 & $0.38 * * *$ & Risk taking $>$ preferred online payment & 3 \\
\hline Accepted & & & 3.02 & $0.27 * *$ & Knowledge internet $>$ preferred online payment & 4 \\
\hline Accepted & & & 3.12 & $0.26^{* *}$ & $\begin{array}{l}\text { Knowledge online payment }<\text { preferred online } \\
\text { payment }\end{array}$ & 5 \\
\hline Accepted & $\begin{array}{l}\text { Toward tendency } \\
\text { internet payment }\end{array}$ & $\begin{array}{l}\text { to use } \\
\text { gateway }\end{array}$ & 2.65 & $-0.08 * *$ & $\begin{array}{l}\text { Risk perception of knowledge management } \\
\text { tools }>\text { internet payment gateway you want to } \\
\text { use online shopping }\end{array}$ & 6 \\
\hline Accepted & 0.07 & & 28.42 & $0.83 * * *$ & $\begin{array}{l}\text { Preferred online payment }<\text { tend to use online } \\
\text { payment online shopping portal }\end{array}$ & 7 \\
\hline
\end{tabular}

$* p<0.05, * * p<0.01, * * * p<0.001$

Hypothesis 1) increasing the customer's risk appetite, risk perceived of knowledge management tool is decreased Results of table 4 shows the effect of risk taking on perceived risk to the value of -0.32 in 0.01 level is significant, accordingly, it can be said that with the increase in risk taking, risk perceived is reduced and vice versa, accordingly confirmed the hypothesis.

Hypothesis 2) increasing internet customer knowledge decreases the risk perceived associated knowledge management tool.

Results Table 4 shows the effect of customer knowledge of Internet on the risk perceived by the customer is not significant with 0.09 amounts, these findings do not support the hypothesis that the second hypothesis is rejected.

Hypothesis 3) increasing the customer risk taking, prefer payment is increased.

Results of table 4 shows the effect of the preferred online payment with a 0.38 customer risk taking level is significant at level 0.001 , accordingly it can be said increasing risk taking, increases the preferred online payment and vice versa. Therefore, this hypothesis is confirmed.

Hypothesis 4) increasing internet customer knowledge increases preference for the use of online payment.

Results of table 4 shows the effect of the knowledge on preference to the use of online payment with a 0.27 in 0.01 level is significant, on this basis we can say that with increasing internet of knowledge increases preference to the use of online payment and vice versa. Therefore, this hypothesis is confirmed.

Hypothesis 5) increasing customer knowledge online payment increases preference for online payment.

Results of table 4 shows the effect of customer payments online shopping on preference for the use of online payment with a 0.26 in 0.01 level is significant, accordingly it can be said by increase customer knowledge of online payment increases the preference for online payment and vice versa. Therefore, this hypothesis is confirmed.

Hypothesis 6) increasing the perceived risk of customer knowledge management tool reduces tendency to use the payment gateway.

Results of table 4 shows the effect of risk perceived by the customer's willingness to use payment gateway with -0.08 in 0.01 level is significant, accordingly can say that increasing risk perceived by the customer reduces tendency to use the payment gateway and vice versa. Therefore, this hypothesis is confirmed.

Hypothesis 7) increasing customer preference for online payments increases tendency to use payment gateway.

Results of table 4 shows the effect on the willingness to use the payment gateway preferred online payment online shopping with a 0.83 in 0.001 level is significant, accordingly, we can say by the preferred online payment, online payment gateway you want to use in online shopping increases, and vice versa. Therefore, this hypothesis is confirmed.

Also, results in Table 4 show that the risk taking variables and internet knowledge to be able to predict the amount $6 \%$ of the variance of their perceived risk, that value has been weak and demonstrates that these two variables cannot be used to predict the perceived risk, also internet knowledge, knowledge of online payment and risk taking would be able to predict online payment preference 79 percent payment and this quantity is high. On the other hand, prefer online payment and risk perception variables also tend to use $72 \%$ of the variance explained that the payment gateway is a high value.

\section{Discussion and Conclusion}


H1: whatever client have high risk taking, the risk perceived by the customer knowledge management tool is less.

Results have revealed that the risk taking effect on perceived risk is significant with a -0.32 in 0.01 level, accordingly it can be said that with the increase in risk taking, risk perception decreases and vice versa, accordingly, first hypothesis is confirmed.

Risk-taking is an inherent state which varies in different people. An individual with lower risk taking perceive lower risk of working and observing knowledge management tools. Perceived risk has different aspects such as financial, social, technological, etc. and in this study; this perceived risk of research using new technology that is intended to be a risk, less risk of knowledge management tools.

$\mathrm{H} 2$ : whatever customer knowledge internet is greater, the perceived risk is less about knowledge management tool.

Results have indicated that the effect of internet customers on perceived risk is 0.09 ; these findings are not accepted the third hypothesis in the third hypothesis is rejected.

As already noted knowledge of the Internet to experience the internet is used and is defined as: The ability or skill with the consumer and to describe the site and use many different services on different websites such as online shopping payment methods. Due to the lack of knowledge management tools in their websites and organizations to experience the different knowledge management tools with the experience of working with the Internet, it can be said necessarily increase knowledge of the Internet reduces the perceived risk is not knowledge management tools.

H3: whatever client has high risk taking, online payment preference is increased.

Results have revealed that the risk taking with value customer's preferred online payment 0.38 in 0.001 level is significant, accordingly it can be said with increased risk taking client, the preferred online payment by him will rise and vice versa. Therefore, this hypothesis is confirmed.

Due to online payment risks, such as financial risks, the risks of personal data (privacy), the risk of technology , selecting an online payment method compared to traditional payment methods has higher risk and accept the inherent risk taking risk Depends to the individual.

H4: whatever customer internet knowledge is greater, online payment preference is more.

Test results showed that the effect of this hypothesis internet customer prefers to use his online payment with value 0.27 in level 0.01 are significant, accordingly can say that with increasing internet customer knowledge, increase preference to the use of online payment and vice versa.

Therefore, this hypothesis is confirmed. Whatever knowledge and customer experience to work with the internet and online shopping will be more familiar with the benefits of online payment and thus prefer payments made via the Internet.

H5: whatever customer knowledge of online payment is greater, online payment preference is increased.

Results have showed that consumer knowledge of online payments on the preference to use online payment with a 0.26 in 0.01 level is significant, accordingly it can be said with increase customer knowledge of online payment, the preference for online payment increases, and vice versa. Therefore, this hypothesis is confirmed.

Payment of goods or services purchased in the online shopping can be done through cash on delivery, pay with credit card at delivery, deposit to account of the seller, payment through the internet portal. If the client knows the advantages and disadvantages of online shopping payment methods use online payment method.

H6: whatever risk perceived by the customer associated with the customer's knowledge management tool is greater, tendency to use the payment gateway is reduced.

Results have indicated that the effects of risk perception by the customer's willingness to pay to use the port with value -0.08 in 0.01 level is significant, accordingly can say that increasing risk perceived by the customer reduces tendency to use the payment gateway and vice versa. Therefore, this hypothesis is confirmed.

As mentioned in Chapter 3, knowledge management tools in the web site contains a shared database, repositories of documents, work flow application process can be found in chapter four that all three of these are effective on the customer's perceived risk.

Shared database 0.84 , documents archive 0.89 , working flow applications 0.79 are significant in confidence level of 0.001 and reservoirs documents has highest amount of influence on their perceived risk, which shows that in 
presentation of catalogs and promotional information and issues organizations must be careful, because it is possible a customer to a fake website and buy withdraw. Also application working flow has minimal impact on perceived risk, which in the site can use these tools to communicate with customers.

H7: whatever customer online payment preference is greater, tend to use payment gateway is increased.

Results have showed that the tendency to use preferred online payment online payment online shopping portal with a 0.83 in 0.001 level is significant, accordingly, we can say increasing preferred online payment, feel free to use the payment gateway will rise and vice versa. Therefore, this hypothesis is confirmed.

\section{Conclusion}

As the results show that people perceive risk, despite any different knowledge management tools in the club Pasargad Bank customers, the greatest risk was belong to tanks documents, according to the results of Directors recommended to pay attention to ads and catalogs, as far as possible in the ports, reduced advertising of products so that customers are not confused and do not give up than shopping.

The low perceived risk associated with work flow applications shows the fact that service firms such as banks should be approved at every stage of a transaction and enters the next stage Divorced answer to our customers. This definitely gives customers confidence that their requests have been made correctly and at the right time and encourages them to do online shopping.

Research limitations

In this study, there are two major limitations. The limitations include lack of research in the field of e-commerce and customer knowledge management and little information about the way individuals and managers to e-commerce in Iran. Most studies have described the theoretical and practical issues and less on these topics was given. Second limitation is low cooperation, particularly in response to the electronic questionnaires.

\section{Scientific and Practical Suggestions}

Due to the requirement to use knowledge management tools for customer relationship information and the loyal customers or current customer and on the other hand risks involved in using these tools, banks must advertising and customer training in order to prepare to deal with these tools, these tools have no negative impact on the willingness of customers to shop online.

Also recommended that administrators by providing an environment where customers can ask their questions in order to reduce the risk perceived.

Among Club members of customers in the Pasargad Bank, website reservoirs documents would be the greatest risk perception. Here, the directors are recommended to limit use of this tool and minimize the perceived risk through necessary training to customers

But lowest risk is associated to application working flow on the web site. So to managers who want to encourage their customers to use their services through their website, recommended to inform their customers through tools such as e-mail or SMS in the course of their service to customers ensure the integrity of the procurement process.

At the end, it is recommended to perform researches in other communities to allow comparison of results and more to. Also, other customer knowledge management tools in addition to instruments mentioned in this study are Wikis, Weblogs, etc. can also be examined in future research.

\section{References}

Aryani, N., \& Irani, F. N. (2014). investigating in the impact of information technology on utilization pervasive quality management (a case study). International Journal of Academic Research, 2014. http://dx.doi.org/10.7813/2075-4124.2014/6-2/A.14

Binder, J. (2014). Online Channel Integration Value Creation and Customer Reactions in Online and Physical $\begin{array}{lllll}\text { Stores. Dissertation Universität St. Gallen, } & \text { Schweiz, } & 2014 .\end{array}$ http://dx.doi.org/10.1007/978-3-658-04573-9verdi.unisg.ch

Gerald, G. G. G. (2006). Knowledge management practices in multimedia super corridor status companies in Malaysia. Retrieved from http://eprints.usq.edu.au

Hashemi, N., \& Nastaran, H. (2012). How brand awareness affects online purchase intention: considering the role of perceived risk. International Journal of Electronic Customer Relationship Management, 2012. http://dx.doi.org/10.1504/IJECRM.2012.051878

Lopez-Nicolas, C. (2007). Customer Knowledge Management and E-commerce: The role of customer perceived 
risk. International Journal of Information Management, 2008(4). http://dx.doi.org/10.1016/j.ijinfomgt.2007.09.001

Ogunde A. O., Folorunso O., Adewale O. S., logunleye G. O., lajayi, A. O. Ogunde, A. O., et. al. (2010). Towards an agent-based customer knowledge management system (ABCKMS) in e-commerce organizations. (IJCSE) International Journal on Computer Science and Engineering, 2(6), 2181-2186. Retrieved from http://www.enggjournals.com

Ömer, F. Ü. (2013). relationship between the dimensions of organizational citizenship behavior and the facets of job satisfaction (an empirical study in a group ofcompanies in turkey wei. International Academic Conference Proceedings, 14-16. Antalya, Turkey.

Salehi, A. (2013). Barriers and Challenges of E-Commerce in Iran. Advances in Environmental Biology, 2013, 1776-1781. ISSN 1995-0756

Sinha, K. M. (2013). Innovation Process: an Integrated Analysis of the Role played by Various Actors. Retrieved from http://eprints.luiss.it

Taghavi, M., Nikoomaram, H., \& Tootian, S. (2011). Comparing Impact of Administrative Corruption on Economic Growth in Developing Countries. Retrieved from http://www.ijmbr.org

Taghavi, M., Nikoomaram, H., \& Tootian, S. (2011). Customer Knowledge Management Framework in E-commerce. Int. J. Manag. Bus. Res., 1(2), 93-98, Spring 2011@IA. Retrieved from http://www.ipedr.com/vol25/27-ICEME2011-N00038.pdf

Zeydabadi, H., Nejad, R., Samizadeh, A. H. (2011). Process of Risk Analysis for Iranian Insurance Companies. Int. J. Manag. Bus. Res., 1(4), 185-198, Autumn 2011, (C) IAU.

\section{Copyrights}

Copyright for this article is retained by the author(s), with first publication rights granted to the journal.

This is an open-access article distributed under the terms and conditions of the Creative Commons Attribution license (http://creativecommons.org/licenses/by/3.0/). 